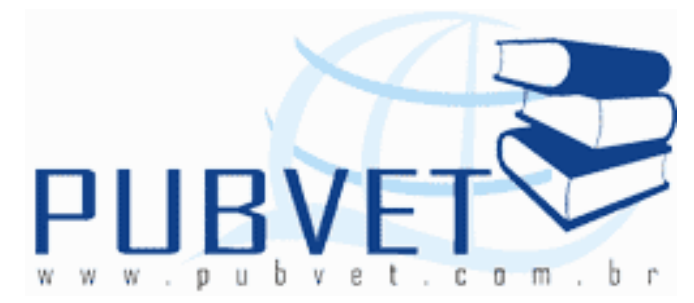

PUBVET, Publicações em Medicina Veterinária e Zootecnia.

\title{
Uso de Thuya occidentalis no tratamento da Papilomatose oral canina
}

Raphael Nikolas Lira ${ }^{*}$, Marthin Raboch Lempek ${ }^{2}$, Paulo Vinícius Tertuliano Marinho ${ }^{3}$, Camila de Castro Neves ${ }^{4}$, Heitor Remonti Trombini ${ }^{1}$

${ }^{1}$ Médico Veterinário autônomo.

${ }^{2}$ Discente do curso de Medicina Veterinária, Universidade do Estado de Santa Catarina - UDESC, Lages - Santa Catarina, Brasil.

${ }^{3}$ Residente do Hospital Veterinário Governador Naudo Latel, setor de Clínica Cirúrgica de Pequenos Animais (CCPA), FCAV - UNESP, Jaboticabal - SP.

${ }^{4}$ Professora Doutora em Cirurgia Veterinária, FCAV - UNESP, Jaboticabal - SP.

* Endereço para correspondência: raphaelira@hotmail.com

\section{Resumo}

A Papilomatose canina é uma doença causada por um vírus não envelopado do gênero Papillomavírus. A forma oral é a apresentação mais comum da doença e desenvolvem-se como verrugas semelhantes à couve-flor. $O$ presente trabalho tem como objetivo relatar o sucesso terapêutico com o uso de Thuya occidentalis $30 \mathrm{CH}$ durante 30 dias em um caso de papilomatose oral canina, não havendo recidiva até o presente momento ( 8 meses).

Palavras-chave: Papilomatose, vírus, couve-flor, Thuya occidentalis. 
LIRA, R.N. et al. Uso de Thuya occidentalis no tratamento da Papilomatose oral canina. PUBVET, Londrina, V. 6, N. 16, Ed. 203, Art. 1360, 2012.

\title{
Use of Thuya occidentalis in the treatment of canine oral papilomatosis
}

\begin{abstract}
The canine papillomatosis is a disease caused by a non-enveloped virus of the genus Papillomavirus. The oral form is the most common presentation of the disease and develops as like a cauliflower. This paper aims to report the successful treatment with the use of 30 days of Thuya occidentalis in a case of canine oral papillomatosis, with no recurrence to date (8 months).
\end{abstract}

Keywords: Papilomatosis, virus, cauliflower, Thuya occidentalis.

\section{Introdução}

A Papilomatose canina é causada por um vírus do gênero Papillomavírus, família Papovaviridae. O Papilomavírus possui simetria icosaédrica, formados por DNA de fita dupla e ausência de envelope. Esta característica o confere maior resistência viral ambiental, sendo resistente ao $\mathrm{pH}$ ácido, éter e aos solventes lipídicos (WALL \& CALVERT, 2006).

Acomete predominantemente cães jovens ou adultos imunossuprimidos (NICHOLLS \& STANLEY, 2000). Não há predileção por sexo, raça dos animais e sazonalidade na ocorrência da doença. A transmissão ocorre por contato direto, indireto com secreções ou sangue provenientes dos papilomas, embora lesões na superfície epitelial favoreçam a infecção (WALL \& CALVERT, 2006).

A forma oral da doença é a mais comum, podendo também ser encontrada na forma ocular e cutânea. Notam-se massas tumorais que se desenvolvem ao longo de 4 a 6 semanas, assumindo forma de verrugas semelhantes à couve-flor nos bordos dos lábios, mucosa bucal, língua, palato, faringe e epiglote. Sinais clínicos comuns incluem halitose, ptialismo, sangramento bucal e relutância em se alimentar (SHERDING, 2008).

O diagnóstico se baseia pelo histórico, aspecto das lesões, e sinais clínicos. O tratamento é controverso e varia desde ao não tratamento e 
LIRA, R.N. et al. Uso de Thuya occidentalis no tratamento da Papilomatose oral canina. PUBVET, Londrina, V. 6, N. 16, Ed. 203, Art. 1360, 2012.

regressão espontânea (dentro de 3 meses), remoção cirúrgica ou crioterapia, quimioterapia com vincristina ou ciclofosfamida, e vacinas autógenas (SHERDING, 2008). Há relatos de terapia única oral com Thuya occidentalis conferindo regressão total após 21 dias de tratamento (BENITES \& MELVILLE, 2003).

\section{Relato de caso}

Foi atendido no consultório Veterinário A La Mi Au, situado na cidade de Itajaí, Santa Catarina, um cão sem raça definida, $11 \mathrm{Kg}$, com queixa de sangramento, salivação excessiva e presença de massas tumorais em região oral. Não foi possível estimar a evolução das massas, porque conforme a responsável o animal era errante e foi achado no mesmo dia. Ao exame físico notou-se apatia, magreza, mucosas róseas, temperatura retal de 38,7 ${ }^{\circ} \mathrm{C}$, sialorréia, sangramento bucal, presença de massas róseas com aspecto de couve-flor em região labial e em palato duro.

O diagnóstico foi realizado por meio dos sinais clínicos e visualização direta das massas. Os papilomas eram de consistência dura, com aspecto de verrugas, desuniformes, de coloração branco-amarelada a enegrecida, variando de pequenos nódulos a grandes, diagnosticando-se Papilomatose oral canina (Figura 1).

Foi instituído tratamento clínico com Thuya occidentalis $30 \mathrm{CH}$, administrado por via oral a cada 12 horas, por 30 dias. No $15^{\circ}$ dia o cão apresentou remissão quase completa dos papilomas, restando apenas alguns resquícios (Figura 2). No $24^{\circ}$ dia ocorreu remissão completa (Figura 3), porém foi mantido o tratamento por mais 1 semana a fim de se evitar recidivas. Até o presente momento não houve recidiva ( 8 meses). 

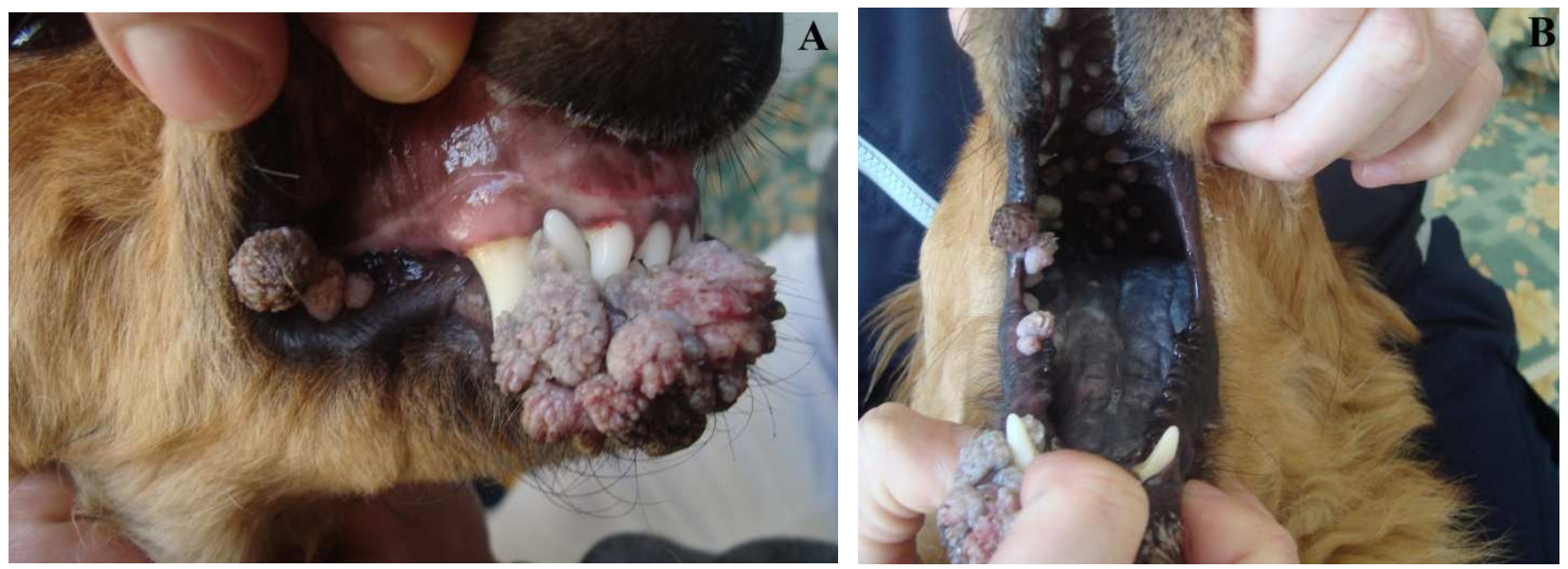

Figura 1. Papilomatose oral canina, momento diagnóstico. (A) Papilomas com aspecto de "couve-flor" de coloração branco amarelada à enegrecida em comissura e mucosa labial. (B) Notar presença em palato duro e mole.
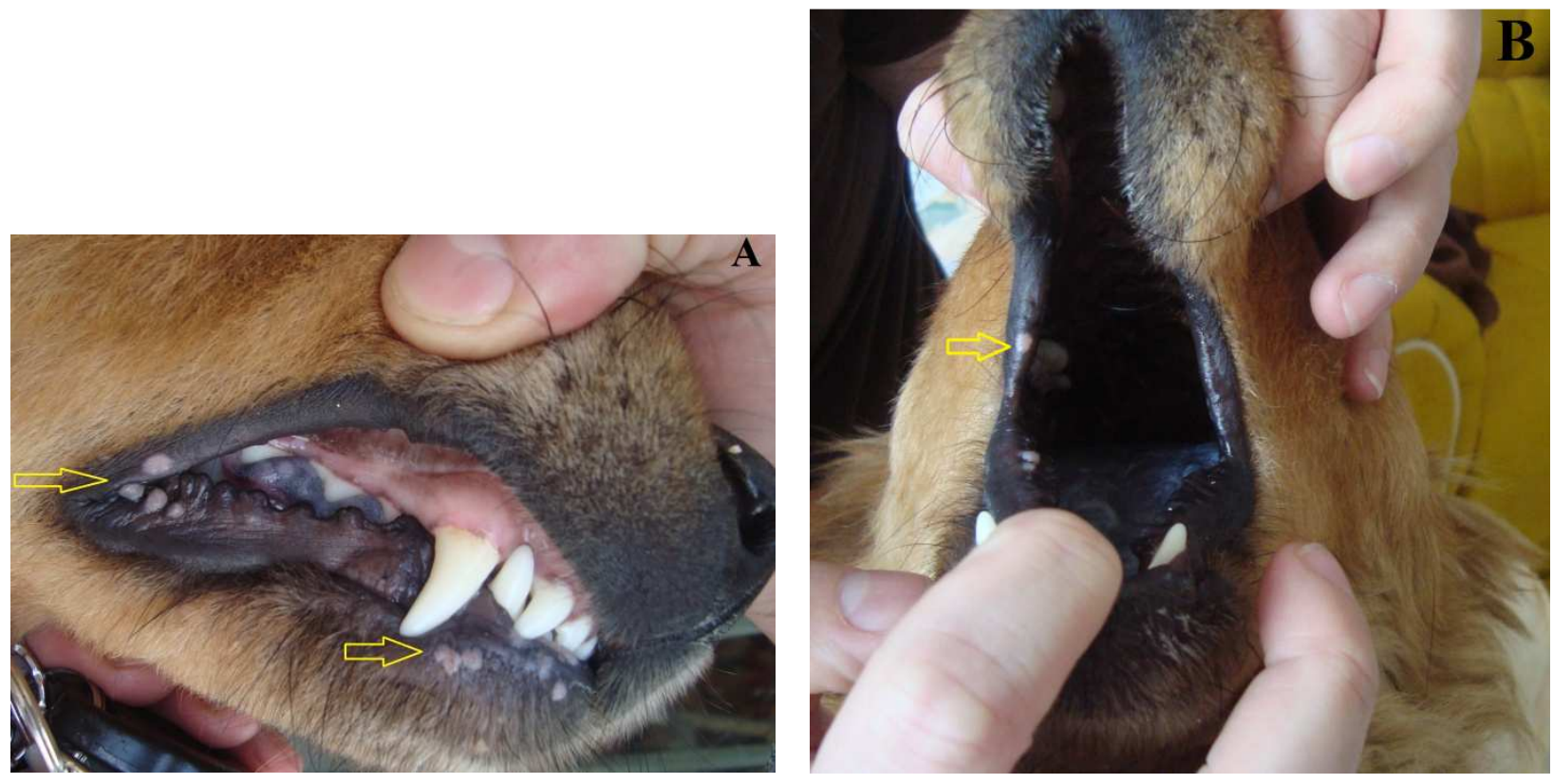

Figura 2. Evolução após 15 dias de tratamento com Thuya occidentalis. (A) e (B) Notar presença de alguns resquícios (setas). 


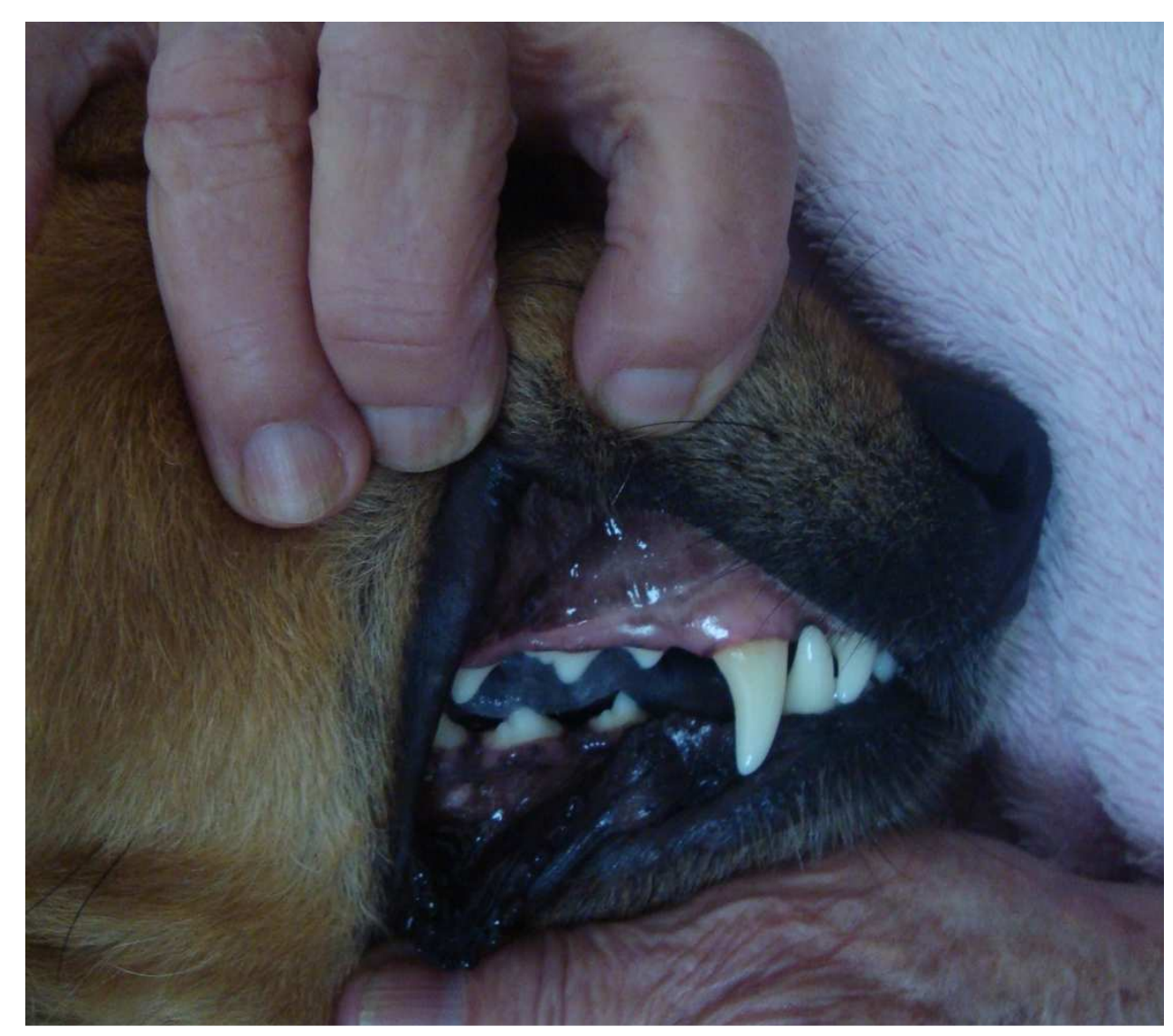

Figura 3. Evolução após 24 dias de tratamento com Thuya occidentalis. Notar remissão completa das lesões.

\section{Discussão}

A papilomatose oral canina comumente ocorre em cães jovens, com menos de um ano de idade (DUMON et al., 2005), cujo sistema imune não está completamente maduro, reforçando o comportamento oportunista do vírus (NICHOLS \& STANLEY, 2000; WALL \& CALVERT, 2006). Além disso, a predominância de lesões na cavidade oral da enfermidade está correlacionada com a ingestão de água e alimentos contaminados, lambedura de secreções contendo partículas virais, traumatismos e/ou pequenas soluções de continuidade. Estas formas representam as principais vias de transmissão da doença nos cães (FERNANDES et al., 2009).

O diagnóstico é realizado por meio dos sinais clínicos, histopatologia da pele e imunohistoquímica de amostras obtidas por biópsia (MEDLEAU \& 
LIRA, R.N. et al. Uso de Thuya occidentalis no tratamento da Papilomatose oral canina. PUBVET, Londrina, V. 6, N. 16, Ed. 203, Art. 1360, 2012.

HNILICA, 2003). O diagnóstico diferencial são os epúlides fibromatosos, tumor venéreo transmissível e se tiver ulcerado o carcinoma de células escamosas, (TILLEY \& SMITH Jr., 2003).

Em consonância com Calvert (1998) e Corrêa \& Corrêa (1992), que referiram a ocorrência de papilomas na cavidade oral como a principal forma de apresentação clínica da papilomatose em cães, nesse caso relatado também se observou lesões múltiplas, exclusivamente na região oral (língua, gengiva e palato).

Foi instituído tratamento com Thuya occidentalis $30 \mathrm{CH}$ conforme relatos de regressão total após 21 dias de tratamento (BENITES \& MELVILLE, 2003).

O extrato da Thuya Occidentalis é usado na medicina popular como expectorante, diurético, anti-helmíntico, estimulante e no tratamento do reumatismo. Também é usada no tratamento de cistite e prostatite hipertrófica em homens idosos e mulheres acometidas por incontinência urinária (OLIVEIRA et al., 1997).

As ações da mesma parecem estar relacionadas ao óleo volátil que é estimulante e purificador do sangue. A Thuya occidentalis possui atividade mitogênica, um polissacarídeo que inibe antígenos, e uma transcriptase reversa que são específicos do HIV-1, além de ser indutor do subgrupo de células T e de várias citocinesinas in vitro (OFFERGELD et al., 1992).

O animal recebeu Thuya occidentalis manipulada de acordo com a farmacotécnica homeopática (SILVA, 1977; MARTINEZ, 1983). A escolha da dinamização $(30 \mathrm{CH})$ utilizada baseou-se nas descrições de Zoby (1999).

\section{Conclusão}

O presente estudo reafirma a importância da papilomatose oral como doença oportunista em cães jovens imunossuprimidos, assim como a boa eficiência da Thuya occidentallis como fármaco imunoestimulante no tratamento da doença em cães. 


\section{Referências}

BENITES, N.R.; MELVILLE, P.A. Tratamento homeopático de papilomatose canina. Clínica Veterinária. v. 8, n. 44, p. 19-20, 2003.

CALVERT, C.A. Canine viral papillomatosis. In: GREENE, E.C. (Ed). Infectious diseases of the dog and cat. Philadelphia: W.B. Saunders Company, 1998. p.288-290.

CORRÊA, W.M.; CORRÊA, C.N.M. Enfermidades infecciosas dos animais domésticos. $2^{a}$ ed. Rio de Janeiro: Medsi, 1992. p. 709-713.

DUMON, C.; GARCÍA, F.; MARTÍ, S. et al. Neonatologia e Pediatria: Canina e Felina. São Paulo: Interbook, 2005, p. 197.

FERNANDES, M.C.; RIBEIRO, M.G.; FEDATO, F.P. et al. Papilomatose oral em cães: revisão da literatura e estudo de doze casos. Ciências Agrárias. v. 30, p. 215-224, 2009.

MARTINEZ, J.A. Farmácia homeopática. Buenos Aires: Albatroz, 1983. 268p.

MEDLeAU, L.; HNILICA, K.A. Dermatologia de Pequenos Animais. São Paulo: Roca, 2003. p. $91-92$.

NICHOLLS, P.K.; STANLEY, M.A. The immunology of animal papillomaviruses. Veterinary Immunology and Immunopathology. Amsterdam v. 73, p. 101-127, 2000.

OFFERGELD, R.; REINECKER, C.; GUMZ, E. et al. Mitogenic activity of high molecular polysaccharide fractions isolated from the Cuppressaceae Thuya occidentalis $\mathrm{L}$. enhanced cytokine: production by thyapolysaccaride G. Fraction (TPSg). Leukemia, v. 6, p. 189-191, 1992.

OLIVEIRA, J.F.; BRAGA, A.C.; AVILA, A.S. et. al. Effect of Thuya occidentalis on the labeling of red blood cells and plasma proteins with technetium-99m. Yale Journal of Biology and Medicine. v. 69, p. 489-494, 1997.

SHERDING, R.G. Doenças virais variadas. In: BIRCHARD, S. J.; SHERDING, R. G. Clínica de pequenos animais. São Paulo: Roca, 2008. cap.16, p.178-179.

SILVA, J.B. Farmacotécnica homeopática simplificada. Rio de Janeiro: [s.n.], 1977. 231p.

TILLEY, L.P.; SMITH Jr., F.W.K. Consulta Veterinária em 5 min. $2^{a}$ ed. Barueri: Manole, 2003. p. 1041.

WALL, M.; CALVERT, C.A. Canine viral papillomatosis. In: GREENE, C.E. Infectious disease in the dog and cat. $3^{a}$ ed. Philadelphia: W.B. Saunders, 2006. p. 73-78.

ZOBY, E.C. Homeopatia veterinária: roteiro para o homeopata. In: DIAS, A. F. Manual de técnica homeopática. Rio de Janeiro: Cultura Médica, 1999. cap. 2, p. 64 - 68. 